\title{
Effect of exercise on postprandial endothelial function in adolescent boys
}

\author{
Matthew J. Sedgwick ${ }^{1}$, John G. Morris ${ }^{1}$, Mary E. Nevill ${ }^{1}$, Keith Tolfrey ${ }^{1}$, Alan Nevill $^{2}$ \\ and Laura A. Barrett ${ }^{1 *}$ \\ ${ }^{1}$ Institute of Youth Sport, School of Sport, Exercise and Health Sciences, Loughborough University, Loughborough, \\ Leicestershire LE11 3TU, UK \\ ${ }^{2}$ Research Institute of Healthcare Science, University of Wolverhampton, Wolverhampton WV1 1LY, UK
}

(Submitted 29 February 2012 - Final revision received 5 October 2012 - Accepted 8 October 2012 - First published online 10 December 2012 )

\section{Abstract}

The ingestion of high-fat meals induces a state of endothelial dysfunction in adults. This dysfunction is attenuated by prior exercise. The response of young people to these nutritional and physiological stressors has not been established. Thus, the purpose of the present study was to investigate if a bout of moderate-intensity exercise influenced endothelial function (as indicated by flow-mediated dilation (FMD)) following the ingestion of a high-fat breakfast and lunch in adolescent boys (aged 12.6-14.3 years). Two, $2 \mathrm{~d}$ main trials (control and exercise) were completed by thirteen adolescent boys in a counter-balanced, cross-over design. Participants were inactive on day 1 of the control trial, but completed 60 min of walking at $60 \%$ peak oxygen uptake in the exercise trial. On day 2 , endothelial function was assessed via FMD prior to, and following, ingestion of a high-fat breakfast and lunch. There was no difference in fasting FMD between the control and exercise trial $(P=0.449)$. In the control trial, FMD was reduced by $32 \%$ following consumption of the high-fat breakfast and by $24 \%$ following lunch. In the exercise trial, the corresponding reductions were 6 and $10 \%$, respectively (main effect trial, $P=0 \cdot 002$ ). These results demonstrate that moderate-intensity exercise can attenuate the decline in FMD seen following the consumption of high-fat meals in adolescent boys.

Key words: CHD risk: Flow-mediated dilation: Postprandial lipaemia: TAG

In adults, the ingestion of a single high-fat meal is associated with endothelial dysfunction and elevated TAG concentrations ${ }^{(1-4)}$, and such responses have been shown to be independent risk factors for $\mathrm{CHD}^{(5,6)}$. While the responses to a single high-fat meal may be transient, individuals in Western societies typically consume several meals a day and spend the majority of a day in the postprandial state ${ }^{(7)}$. Consequently, the repeated ingestion of meals high in fat, and the associated exposure to repeated endothelial dysfunction and elevated TAG concentrations, may have important implications on long-term vascular health.

The presence of fatty streaks in children confirms that CHD has its origins early in life ${ }^{(8)}$. Researchers have also noted the high prevalence and rapid progression of raised lesions in the arteries of adolescents and young adults ${ }^{(9)}$. As CHD is typically a chronic condition, which progresses and develops over decades ${ }^{(10)}$, an understanding of the factors that augment and attenuate the development of the disease, even in the young, could have important clinical implications, particularly when it has been argued that the greatest benefit from a treatment occurs the earlier it is initiated ${ }^{(11)}$. Endothelial dysfunction is considered to be the first stage in atherogenesis $^{(12)}$ and appears to be a pre-requisite for the development of atherosclerosis ${ }^{(13)}$.

In adults, many of the interventions used to combat $\mathrm{CHD}$ involve pharmacological therapies that, while often effective, can be costly and have numerous side effects, especially if undertaken for a prolonged period ${ }^{(14)}$. In addition, the safety and efficacy of many pharmacological treatments have not been established in young people. Exercise has been shown to attenuate the endothelial dysfunction ${ }^{(1,3)}$ and rise in TAG concentrations ${ }^{(15)}$ seen following the ingestion of a high-fat meal in adults. While exercise may induce similar responses in children and adolescents, this is by no means certain, because as children and adolescents grow and mature, their physiological responses to exercise may vary ${ }^{(16)}$. Recently, it has been reported that exercise can reduce postprandial TAG concentrations in adolescents ${ }^{(17-20)}$, but, to our knowledge, no study has investigated the effect of exercise on postprandial endothelial function.

Therefore, the primary aim of the present study was to investigate if a bout of moderate-intensity exercise influenced

Abbreviations: FMD, flow-mediated dilation; HOMA-IR, homeostatic model assessment of insulin resistance.

*Corresponding author: Dr L. A. Barrett, fax +44 1509 226301, email l.a.barrett@lboro.ac.uk 
endothelial function (as indicated by flow-mediated dilation (FMD)) following the ingestion of a high-fat breakfast and lunch in adolescent boys.

\section{Experimental methods}

\section{Participants}

A total of fifteen adolescent boys (aged 12.6-14.3 years, Tanner stages $1-5$ (median 4)) volunteered to participate, with thirteen boys completing the study. Non-completion of the study was due to either syncope during blood sampling or a participant's lack of time. The study was conducted according to the guidelines laid down in the Declaration of Helsinki, and all procedures were approved by the Loughborough University Ethical Advisory Committee. Before any testing took place, all participants had the procedures and risks associated with involvement in the study explained to them. Written assent from each participant and written consent from a parent were then obtained. All participants were apparently healthy and not taking any drugs known to affect lipid or carbohydrate metabolism; the physical characteristics of those who completed the study are shown in Table 1.

\section{Study design}

Participants completed preliminary tests and then undertook two, $2 \mathrm{~d}$ main trials that were separated by $7 \mathrm{~d}$ (control trial and exercise trial) in a $2 \times 2$ replicated (seven replicates) Latin square design.

\section{Preliminary tests}

Height and sitting height were measured to the nearest $0 \cdot 1 \mathrm{~cm}$ using a wall-mounted stadiometer (Seca) and body mass was measured to the nearest $0.01 \mathrm{~kg}$ using a beam balance scale (Avery). Skinfold thicknesses were measured to the nearest $0.2 \mathrm{~mm}$ at four sites (biceps, triceps, subscapular and suprailiac) using callipers (Harpenden; Baty International),

Table 1. Physical characteristics of participants (Mean values and standard deviations, $n$ 13)

\begin{tabular}{lcc}
\hline & Mean & SD \\
\hline Age (years) & $13 \cdot 6$ & 0.6 \\
Height (m) & 1.57 & 0.12 \\
Body mass (kg) & $56 \cdot 2$ & $17 \cdot 1$ \\
BMl (kg/m ${ }^{2}$ ) & 22.3 & 4.2 \\
Sum of four skinfolds (mm)* & 44.4 & 20 \\
Waist circumference (cm) & 71.6 & 9.2 \\
Hip circumference (cm) & 89.5 & 11.2 \\
Waist:hip ratio & 0.80 & 0.02 \\
SBP (mmHg) & 116 & 9 \\
DBP (mmHg) & 67 & 7 \\
Age from PHV (years) & -0.7 & 1.0 \\
VO 2 peak (ml/kg per min) & $48 \cdot 1$ & 7.5 \\
\hline
\end{tabular}

$\mathrm{SBP}$, systolic blood pressure; DBP, diastolic blood pressure; PHV, peak height velocity; $\mathrm{VO}_{2}$ peak, peak oxygen uptake.

* Four skinfold sites were biceps, triceps, subscapular and suprailiac. and waist and hip circumferences were measured to the nearest $0 \cdot 1 \mathrm{~cm}$. Each participant was asked to make a selfassessment of maturity based on secondary sexual characteristics $^{(21)}$, and age from peak height velocity was also estimated $^{(22)}$. Finally, peak oxygen uptake $\left(\mathrm{VO}_{2}\right.$ peak) was measured and the relationship between oxygen uptake and treadmill incline was established ${ }^{(17)}$.

\section{Main trials}

Participants were instructed to refrain from physical activity for $2 \mathrm{~d}$ and not to consume alcohol or supplements in the $7 \mathrm{~d}$ before the main trials. Participants also completed a food diary for $2 \mathrm{~d}$ before the first main trial and were asked to replicate this diet for the subsequent trial.

On day 1 of the control trial, the participants were physically inactive, whereas in the exercise trial, they reported to the laboratory at 16.00 hours and walked on a treadmill at $60 \% \mathrm{VO}_{2}$ peak for $60 \mathrm{~min}$. The walking was divided into four $15 \mathrm{~min}$ blocks interspersed with 3 min rest periods. Heart rate, ratings of perceived exertion and expired air samples were collected in the last minute of each block. Energy expenditure was estimated using indirect calorimetry ${ }^{(23)}$.

On day 2 of each main trial, participants reported to the laboratory at 08.00 hours, following an overnight fast, and FMD was assessed and a capillary blood sample collected. Participants then ate breakfast and a clock was started on the commencement of the meal. After breakfast, the participants rested for $6.5 \mathrm{~h}$. Lunch was provided at $3.5 \mathrm{~h}$. FMD was assessed again at 3 and $6.5 \mathrm{~h}$, and additional blood samples collected at $0.5,1,3,4,4.5$ and $6.5 \mathrm{~h}$.

\section{Meals}

Breakfast consisted of croissant, chocolate spread and a chocolate milkshake (chocolate power, whole-fat milk and double cream), providing $1.5 \mathrm{~g}$ fat $(60 \%), 1.8 \mathrm{~g}$ carbohydrate (33\%), $0.4 \mathrm{~g}$ protein $(7 \%)$ and $92.9 \mathrm{~kJ} / \mathrm{kg}$ body mass. Participants were given $15 \mathrm{~min}$ to consume breakfast. Lunch consisted of a cheese sandwich (white bread, butter and cheese), ready salted potato chips and a chocolate milkshake (chocolate powder and whole-fat milk), providing $1.1 \mathrm{~g}$ fat (50\%), $1.9 \mathrm{~g}$ carbohydrate $(37 \%), 0.6 \mathrm{~g}$ protein $(13 \%)$ and $84.6 \mathrm{~kJ} / \mathrm{kg}$ of body mass. Participants were given $20 \mathrm{~min}$ to consume lunch. Participants consumed water ad libitum during the first trial and any intake was replicated in the subsequent trial.

\section{Endothelial function assessment by flow-mediated dilation}

FMD measurements were made using previously published guidelines and recommendations ${ }^{(24-26)}$. Briefly, for each FMD measurement a pneumatic blood pressure cuff (Hokanson) was placed on the participant's right arm immediately distal to the elbow. Participants then rested in a supine position for $20 \mathrm{~min}$, with their right arm extended at approximately $90^{\circ}$ from their torso. The brachial artery was imaged longitudinally in the distal third of the upper arm 
using ultrasound (11 MHz linear array transducer, attached to a high-resolution ultrasound machine Power Vision 6000; Toshiba). A baseline scan of the artery was conducted over twenty consecutive cardiac cycles. Then, the blood pressure cuff was inflated to $200 \mathrm{mmHg}$ for $5 \mathrm{~min}$. Further images were captured continuously following cuff release for $3 \mathrm{~min}$. Images were captured on the r-wave of each cardiac cycle (Vascular Imager, version 4.1.3; Medical Imaging Applications LLC).

Ultrasound settings (gain, focus zone and depth) were set to optimise longitudinal B-mode images of the lumenarterial wall interface. Pulsed-wave Doppler was used, simultaneously with B-mode imaging, to assess blood flow velocity; data were collected at an insonation angle $\leq 70^{\circ}$, with the sample volume minimised and positioned in the centre of the artery. Ultrasound settings were standardised for each participant for every subsequent measurement. Measurement location was also standardised for each participant based on anatomical landmarks, snapshot images and an ink marker placed on the skin that was maintained between trials.

Recorded images were later digitised using specialised edge-detection and wall-tracking software (Brachial analyzer, version 4.1.3; Medical Imaging Applications LLC). Peak diameter following occlusion was determined using a three-frame moving average. FMD was calculated as the percentage change from basal diameter to peak diameter, and was also normalised for the post-occlusion shear rate ${ }^{(25)}$

$\mathrm{CV}$ made on measurements made $7 \mathrm{~d}$ apart for fasting basal diameter and FMD in our laboratory were 0.6 and $9.7 \%$ and in the postprandial state were 0.8 and $10.0 \%$, respectively.

\section{Blood sampling and biochemical analysis}

From a warmed left hand, capillary blood was collected into $500 \mu \mathrm{l}$ potassium-EDTA-coated microvettes (Sarstedt) and immediately centrifuged at $1500 \mathrm{~g}$ for $10 \mathrm{~min}$ at $4^{\circ} \mathrm{C}$. The resulting plasma was then stored at $-20^{\circ} \mathrm{C}$ for later analysis. Plasma TAG and glucose concentrations were determined by enzymatic and colorimetric methods (HORIBA ABX Diagnostics). Plasma insulin concentration was determined by ELISA (Mercodia). Within-batch $\mathrm{CV}$ were as follows: TAG $1.2 \%$, glucose $0.5 \%$ and insulin $8.8 \%$.

\section{Statistical analysis}

Data were analysed using the PASW statistics software version 18.0 for Windows (SPSS, Inc.). The total and incremental (after correcting for fasting concentrations) area under the plasma concentration $v$. time curves for TAG, glucose and insulin were calculated using the trapezium rule. Insulin resistance was evaluated according to the homeostatic model assessment of insulin resistance (HOMA-IR) ${ }^{(27)}$. Residual errors were tested for normality using the Shapiro-Wilk test and, where necessary, data were logarithmically transformed prior to statistical analysis. Fasting basal diameter, peak diameter, FMD, normalised FMD and plasma TAG, glucose and insulin concentration, area under the plasma concentration $v$. time curves and HOMA-IR were compared between trials using paired Student's $t$ test. A mixed-effects general linear model with two fixed factors (trial and time) and one random factor (participant) was used to compare differences between trials over time, and any possible interactions between trial and time, for basal diameter, peak diameter, FMD, normalised FMD and plasma TAG and glucose and insulin concentrations. For further information on this design and analysis, see Winer $^{(28)}$. Where there was a violation of compound symmetry, based on Mauchly's test, the df were adjusted using the Huynh-Feldt epsilon. The least significant difference was used to identify exactly where any main effects of time lay. When a significant trial $\times$ time interaction was revealed, targeted pairwise comparisons were used, specifically comparisons within trials with respect to the fasting measure and between trials at the same time point. Pearson's correlation coefficient was calculated in the control and in the exercise trial for fasting plasma TAG concentration and fasting FMD; for the change in FMD and the total area under the plasma TAG concentration $v$. time curve from 0 to $3 \mathrm{~h}$; and for the change in FMD and the total area under the plasma TAG concentration $v$. time curves from 0 to $6.5 \mathrm{~h}$ ( total). Statistical significance was accepted at the $P<0.05$ level. All participant characteristics are presented as population marginal mean and standard deviation, and all experimental data are presented as population marginal mean and standard error.

\section{Results}

\section{Responses to treadmill exercise}

Mean oxygen uptake during the bouts of walking was $28 \cdot 8$ (SEM 1.3) $\mathrm{ml} / \mathrm{kg}$ per min, which represented 59.9 (SEM 0.4) \% of the participants' $\mathrm{VO}_{2}$ peak. Mean heart rate, ratings of perceived exertion and gross energy expenditure were 156 (SEM 2) beats/min, 12 (SEM 1) and 1.92 (SEM 0.41) MJ or 34.9 (SEM 1.5$) \mathrm{kJ} / \mathrm{kg}$ body mass, respectively.

\section{Measures in the fasted state}

No differences were observed between trials for fasting basal diameter (Table 2, $P=0.471$ ), peak diameter (Table 2, $P=0.707)$, FMD (Fig. 1(a), $P=0.449$ ), normalised FMD (Fig. 1(b), $P=0.379$ ), plasma glucose concentration (Fig. 2(b), $P=0 \cdot 190$ ) and plasma insulin concentration (Fig. 2(c), $P=0.343)$. No differences were observed between trials for fasting HOMA-IR (control $v$. exercise; $3 \cdot 0$ (SEM 0.5) v. 2.8 (SEM 0.8), $P=0 \cdot 971)$. The fasting plasma TAG concentration was $0 \cdot 17 \mathrm{mmol} / 1$ lower in the exercise trial (Fig. 2(a); $P=0 \cdot 001$ ).

Measures in the postprandial state: basal diameter, peak diameter, flow-mediated dilation and normalised flowmediated dilation

Basal diameter and peak diameter increased following the ingestion of the high-fat test meals, but did not differ between trials (Table 2; basal diameter: main effect trial $(P=0.239)$, 
Table 2. Basal diameter and peak diameter* of the brachial artery during the measurement of flow-mediated dilation in the control and exercise trials (Mean values with their standard errors, $n 13$ )

\begin{tabular}{|c|c|c|c|c|c|c|c|c|c|c|c|c|}
\hline & \multicolumn{6}{|c|}{ Control } & \multicolumn{6}{|c|}{ Exercise } \\
\hline & \multicolumn{2}{|c|}{$\mathrm{Oh}$} & \multicolumn{2}{|c|}{$3 \mathrm{~h}$} & \multicolumn{2}{|c|}{$6.5 \mathrm{~h}$} & \multicolumn{2}{|c|}{$\mathrm{Oh}$} & \multicolumn{2}{|c|}{$3 \mathrm{~h}$} & \multicolumn{2}{|c|}{$6 \cdot 5 \mathrm{~h}$} \\
\hline & Mean & SEM & Mean & SEM & Mean & SEM & Mean & SEM & Mean & SEM & Mean & SEM \\
\hline Basal diameter $(\mathrm{mm}) \dagger \ddagger$ & 3.54 & 0.15 & 3.64 & 0.15 & 3.70 & 0.15 & 3.51 & 0.15 & 3.60 & 0.14 & 3.61 & 0.15 \\
\hline Peak diameter $(\mathrm{mm}) \ddagger$ & 3.83 & 0.16 & 3.84 & 0.14 & 3.93 & 0.15 & 3.81 & 0.16 & 3.89 & 0.14 & 3.89 & 0.15 \\
\hline
\end{tabular}

* Data were analysed using a mixed-effects general linear model with two fixed factors (trial and time) and one random factor (participant) for both basal and peak diameter: main effect trial, $P>0.05$; main effect trial, $P<0.05$; and interaction effect trial $\times$ time, $P>0.05$. Least significant differences were used to identify where significant main effects lay.

† Main effect - time: difference between 0 and $3.5 \mathrm{~h}(P<0.05)$.

$\ddagger$ Main effect - time: difference between 0 and $6.5 \mathrm{~h}(P<0.05)$.

main effect time $(P<0 \cdot 001)$ and interaction effect trial $\times$ time $(P=0.253)$; peak diameter: main effect trial $(P=0.961)$, main effect time $(P=0.030)$ and interaction effect trial $\times$ time $(P=0 \cdot 190))$.

Postprandial FMD was lower in the control compared with the exercise trial, both before (Fig. 1(a); main effect trial $(P=0.002)$; main effect time $(P=0.023)$; and interaction effect trial $\times$ time $(P=0.088))$ and after (Fig. 1(b); main effect trial ( $P=0.003)$; main effect time $(P=0.002)$; and interaction effect trial $\times$ time $(P=0.036))$ normalisation for the postocclusion shear rate. Pairwise comparisons identified that normalised FMD was significantly lower compared with the fasting measure at both $3 \mathrm{~h}(P=0.005)$ and $6.5 \mathrm{~h}(P=0.013)$ only in the control trial, and that normalised FMD was significantly higher in the exercise trial, compared with the control trial, at $3 \mathrm{~h}(P=0.003)$ and $6.5 \mathrm{~h}(P=0.011)$.

\section{Measures in the postprandial state: TAG, glucose and insulin concentrations}

Postprandial plasma TAG concentration was lower in the exercise compared with the control trial (Fig. 2(a); main effect trial $(P=0.009)$; main effect time $(P<0.001)$; and interaction effect trial $\times$ time $(P=0 \cdot 276))$. The total area under the plasma TAG concentration $v$. time curve was $22 \%$ lower in the exercise compared with the control trial (control $v$. exercise; 12.68 (SEM 1.37) v. $9.84(\operatorname{sem} 0.75) \mathrm{mmol} / 1 \times 6.5 \mathrm{~h}, P=0.018)$. The incremental area under the plasma TAG concentration $v$. time curve was $24 \%$ lower in the exercise compared with the control trial; however, this did not reach statistical significance (control $v$. exercise; $7 \cdot 16$ (SEM 1.22) $v . \quad 5.45$ (sem 0.62$) \mathrm{mmol} / 1 \times 6.5 \mathrm{~h}, P=0 \cdot 169$ ).

Postprandial plasma glucose concentrations did not differ between trials (Fig. 2(b); main effect trial $(P=0.877)$; main effect time $(P<0.001)$; and interaction effect trial $\times$ time $(P=0.367))$. No differences were observed between the exercise and control trials for the total or incremental area under the plasma glucose concentration $v$. time curve (control $v$. exercise; $42.91(\operatorname{SEM} 0.66) v .42 .62(\operatorname{SEM~} 0.83) \mathrm{mmol} / \mathrm{l} \times 6.5 \mathrm{~h}$, $P=0.429$ and 6.77 (SEM 0.97$) \quad v .7 .02 \quad($ SEM 0.73$) \mathrm{mmol} /$ $1 \times 6.5 \mathrm{~h}, P=0.490$, respectively).

Postprandial plasma insulin concentrations did not differ between trials (Fig. 2(c); main effect trial $(P=0 \cdot 078)$; main effect time $(P<0.001)$ and interaction effect trial $\times$ time $(P=0.558))$. However, the total area under the plasma insulin concentration $v$. time curves was lower in the exercise compared with the control trial, but the incremental area under the plasma insulin concentration $v$. time curves was not (control $v$. exercise; 1854.0 (SEM 283.8) $v$. 1713.6 $($ SEM 276.0$) \mathrm{pmol} / 1 \times 6.5 \mathrm{~h}(P=0.047)$ and $1397.4($ SEM 286.8) v. $1298.4(\operatorname{SEM} 189.0) \mathrm{pmol} / \mathrm{l} \times 6.5 \mathrm{~h}(P=0.935)$ respectively $).$

\section{Correlations between flow-mediated dilation and TAG concentrations}

The correlations between fasting FMD and plasma TAG concentrations were as follows: control, $r-0 \cdot 106, P=0.730$; exercise, $r 0 \cdot 104, P=0.736$. The correlations between the change in FMD and the total area under the plasma TAG concentration $v$. time curve from 0 to $3 \mathrm{~h}$ were as follows: control, $r-0 \cdot 138, P=0 \cdot 653$; exercise, $r 0 \cdot 214, P=0 \cdot 482$. The correlations between the change in FMD and the total area under the plasma TAG concentration $v$. time curve from 0 to $6.5 \mathrm{~h}$ were as follows: control, $r 0 \cdot 190, P=0.534$; exercise, $r 0 \cdot 223, P=0.465$.

\section{Discussion}

The key finding of the present study was that, for the first time in adolescent boys, a bout of moderate-intensity exercise was shown to attenuate the decline in FMD observed in a control trial following the ingestion of high-fat meals. In fact, once FMD had been normalised for the post-occlusion shear rate, prior exercise prevented the postprandial decline in FMD entirely. No relationships were found between postprandial FMD and plasma TAG concentrations.

The present study is the first to investigate endothelial function following the ingestion of high-fat meals in adolescent boys. The ingestion of breakfast and lunch containing substantial quantities of fat ( 60 and $50 \%$ by energy content, respectively) reduced FMD by $32 \%$ after breakfast and $24 \%$ after lunch compared with fasting. This observed endothelial dysfunction (as indicated by a decline in FMD) following the consumption of high-fat meals has been demonstrated repeatedly in adults. While this decline in FMD in asymptomatic adults can range between $17^{(29)}$ and $70 \%{ }^{(2)}$, the majority of studies report changes between 30 and $50 \%^{(3,4,30-32)}$. Importantly, 

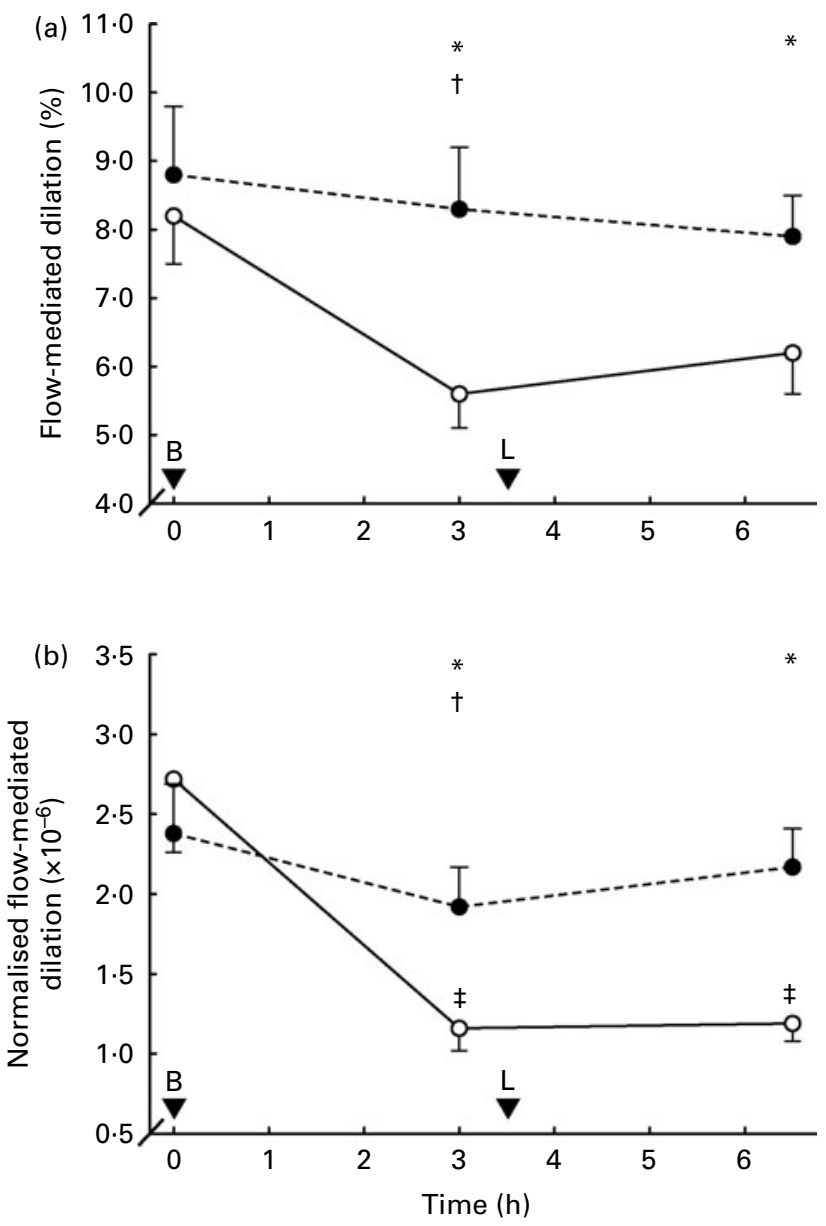

Fig. 1. (a) Flow-mediated dilation and (b) normalised flow-mediated dilation. $B$, breakfast; L, lunch. Values are means, with their standard errors represented by vertical bars $(n 13)$. Data were analysed using a mixed-effects general linear model with two fixed factors (trial and time) and one random factor (participant). Least significant differences post hoc analysis was used to identify where significant main effects lay and when a significant time $\times$ trial interaction was identified, pre-specified planned comparisons were used, specifically comparisons within trial with respect to the fasting measure and between trials at the same time point. (a) Flow-mediated dilation: main effect trial $(P=0.002)$; main effect time $(P=0.023)$; and interaction effect trial $\times$ time ( $P=0.088$ ). (b) Normalised flow-mediated dilation: main effect trial $(P=0.004)$; main effect time $(P=0.004)$; and interaction effect trial $\times$ time $(P=0.040)$. ${ }^{*}$ Difference from $0 \mathrm{~h} \quad(P<0.05)$. †Difference from previous time point $(P<0.05)$. $\ddagger$ Difference from $0 \mathrm{~h}$ in the same trial and difference from exercise trial at the same time point $(P<0.05)$. - - ., Control; - -, exercise.

the adolescent boys in the present study had none of the factors associated with CHD risk. Yet, the consumption of high-fat meals induced endothelial dysfunction to a similar extent to that previously observed in adults. Therefore, the present study supports the assertion that ingestion of meals containing high quantities of fat place strain on the endothelium and clearly demonstrates that this is the case even in healthy adolescents.

The ingestion of high-fat meals is not uncommon in adolescents, with $60 \%$ of teenagers in the USA reported to eat 'fast food' (which is typically high in fat content) at least once a week $^{(33)}$ and $30 \%$ reported to eat such foods every day ${ }^{(34)}$. Therefore, a substantial number of adolescents may be exposed, on a regular basis, to the risks associated with the consumption of meals high in fat. While the observation period in the present study was very short and the endothelial dysfunction following ingestion of a high-fat meal has been shown to be transient, certainly in adults ${ }^{(2,4)}$, if the responses observed in the present study were to be repeated on a regular basis over many years, then the strain on the vasculature could be substantial and have a lasting deleterious effect. Interventions that might reduce or prevent this strain on the vasculature could have important clinical implications. Research with adults suggests that moderate-intensity exercise undertaken before the ingestion of a high-fat meal reduces the subsequent postprandial endothelial dysfunction ${ }^{(1,3)}$. Interestingly, if the exercise is of a high-intensity (85-95\% of maximum heart rate) the dysfunction is prevented ${ }^{(3)}$. In the present study, we observed that after a bout of moderateintensity exercise (performed $14 \mathrm{~h}$ prior to the ingestion of the high-fat breakfast and lunch) the decline in FMD was attenuated. In fact, once FMD had been normalised for the postocclusion shear rate, prior exercise prevented the postprandial decline in FMD entirely, indicating that prior exercise negated the deleterious effects of high-fat meals on the endothelium.

It has been argued that postprandial decreases in FMD do not signify endothelial dysfunction, but are purely a consequence of an increase in basal diameter ${ }^{(31,35)}$. Arteries with large diameters have been shown to exhibit lower FMD than arteries with small diameters ${ }^{(36-39)}$, as the post-occlusion shear stress stimulus (the stimulus for post-occlusion dilation) is inversely related to vessel diameter ${ }^{(36,37)}$. As an increase in mean basal diameter from 0 to $3 \mathrm{~h}$ was observed in both the control and the exercise trial in the present study, which could influence the FMD responses, an attempt was made to account for this increase in basal diameter by normalising FMD to the area under the shear rate $v$. time curves. Normalised FMD is not associated with basal diameter ${ }^{(37,39)}$. As postprandial FMD was lower in the control compared with the exercise trial, both before and after normalisation for the post-occlusion shear rate, despite the similar changes in basal diameter in the control and exercise trials, it is likely that the lower FMD observed in the control trial is not solely a consequence of an increase in basal diameter.

In the present study, as well as observing lower postprandial TAG concentrations following exercise, we also noted a reduction in fasting TAG concentration. The reduction in fasting TAG concentration, seen as a result of exercise in the present study, has also been observed frequently in previous studies $^{(17,40,41)}$. Given that the correlations between fasting TAG concentration and FMD in the control and exercise trials in the present study were low and not statistically significant, it is unlikely that the differences in fasting TAG concentration in the control and exercise trials would have confounded the main results of the study.

In previous research, a relationship between TAG concentrations and FMD has been demonstrated postprandially, but no relationship between these variables was evident in the fasted state ${ }^{(4,42,43)}$. In previous studies, where a relationship has been found between postprandial TAG concentrations and change in endothelial function, Pearson correlations have ranged from $-0 \cdot 31^{(30)}$ to $-0 \cdot 70^{(2)}$. This has led to the 

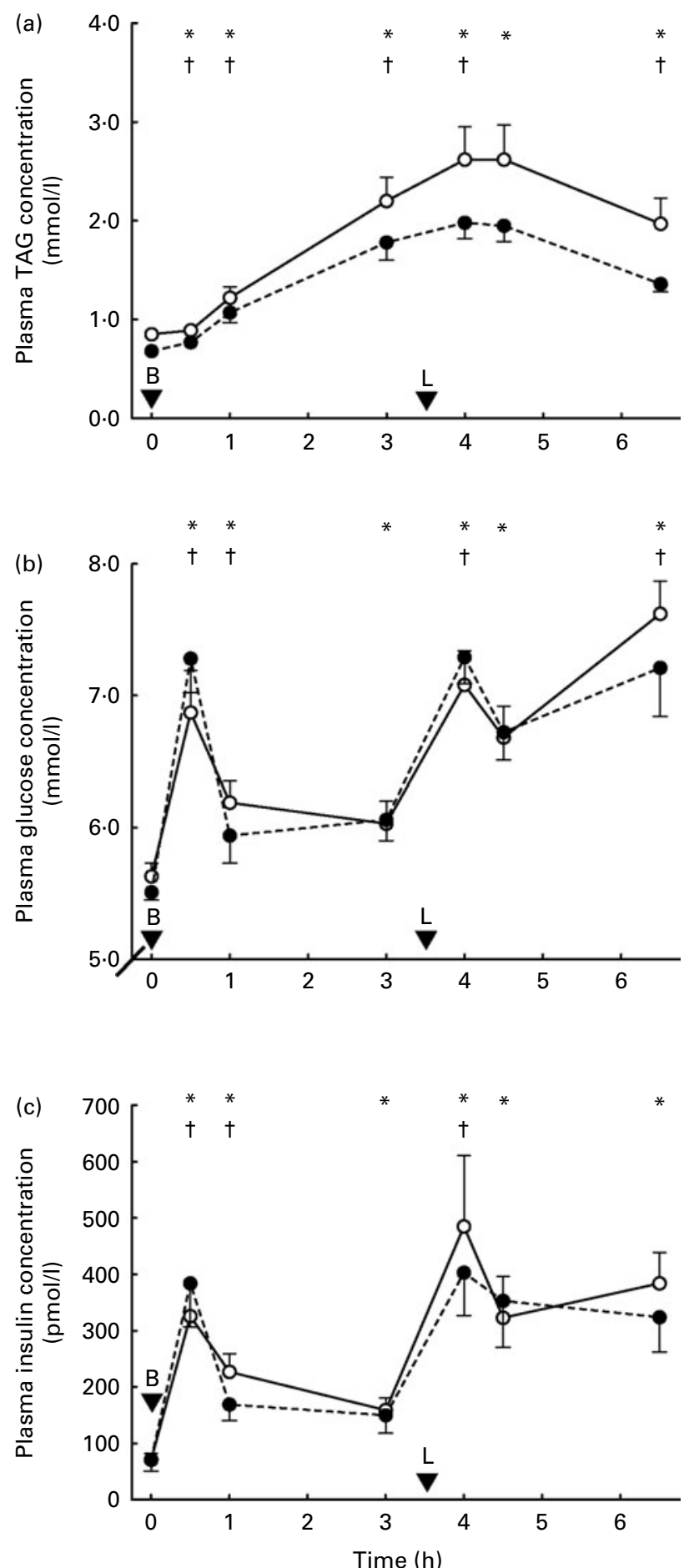

Fig. 2. Plasma (a) TAG, (b) glucose and (c) insulin concentrations. B, breakfast; $L$, lunch. Values are means with their standard errors represented by vertical bars ( $n$ 13). Data were analysed using a mixed-effects general linear model with two fixed factors (trial and time) and one random factor (participant). Least significant differences post hoc analysis was used to identify where significant main effects lay; TAG and insulin data were Ln transformed prior to the analysis. (a) TAG: main effect trial $(P=0.009)$; main effect time $(P<0.001)$; and interaction effect trial $\times$ time $(P=0.276)$. (b) Glucose: main effect trial $(P=0.877)$; main effect time $(P<0.001)$; and interaction effect trial $\times$ time $(P=0.361)$. (c) Insulin: main effect trial $(P=0.078)$; main effect time $(P<0.001)$; and interaction effect trial $\times$ time $(P=0.558)$. ${ }^{*}$ Difference from $0 \mathrm{~h}(P<0.05)$ and †Difference from previous time point $(P<0.05)$. $-\mathrm{O}$, Control; - - , exercise. hypothesis that prior exercise can prevent the postprandial endothelial dysfunction by reducing postprandial TAG concentrations $^{(1)}$. However, not all studies have observed this association (for a review, see Wallace et $a l .{ }^{(44)}$ ). In the present study, postprandial TAG concentrations were lower and FMD higher in the exercise compared with the control trial, but we found no evidence of a direct association between these variables. A lack of association between the exercise-induced changes in TAG concentration and endothelial function has also been noted by Tyldum et al. ${ }^{(3)}$, who found that exercise reduced postprandial endothelial dysfunction but did not affect postprandial TAG concentration. Gill et al. ${ }^{(45)}$ also observed that postprandial endothelial function was similar before and after a period of detraining, despite the postprandial TAG concentration being higher following detraining. There are a number of possible factors that may contribute to the inconsistent associations observed across studies between postprandial TAG and endothelial function, including differences in the methods used to quantify variables, variability in the timing of measurements and in the timing of postprandial events in vivo and differences in the lipid load and in the number of study participants ${ }^{(44,46)}$.

The lack of association between TAG concentration and endothelial function in the present study may suggest that while postprandial changes in TAG concentrations and FMD may coincide, they are not dependent on each other; however, due to the small sample size, such conclusions need to be drawn cautiously. Nonetheless, elevated postprandial TAG concentrations are an independent risk factor for $\mathrm{CHD}^{(6)}$ and, consistent with other reports from the literature that have used a single meal ${ }^{(17-20)}$, the results of the present study demonstrate that exercise reduces postprandial plasma TAG concentrations following the ingestion of two high-fat meals in adolescent boys.

In the exercise trial, despite no change in HOMA-IR, the total area under the plasma insulin concentration $v$. time curve was lower than in the control trial, while glucose concentrations were not different, suggesting that the insulin sensitivity of the participants was improved after exercise. The only other study that has measured both postprandial glucose and insulin concentrations in adolescents following high-fat mixed meals found no effect of exercise ${ }^{(18)}$. When HOMA-IR values were compared between the present study and the study by MacEneaney et al. ${ }^{(18)}$, the participants in the present study were found to be more insulin resistant; this may explain the difference in findings between the two studies. It is well-established that during puberty a transient state of insulin resistance is experienced, with the greatest insulin resistance occurring mid-puberty (Tanner stage 3$)^{(47,48)}$. MacEneaney et al. ${ }^{(18)}$ did not state the pubertal status of the boys in their study; however, the boys were older than those in the present study (15.9 (SD 0.4) v. 13.6 (SD 0.6 ) years, respectively) and therefore would be expected to be more mature and therefore less insulin resistant. Previous studies have identified greater insulin sensitivity in adolescents who are more physically active ${ }^{(49-51)}$ or have undergone a period of exercise training ${ }^{(52,53)}$. The present study suggests that an acute bout of exercise also has the ability to 
improve insulin sensitivity. Clearly, this finding warrants further investigation.

The present study did not directly investigate the mechanisms by which exercise attenuates endothelial dysfunction, but a number of possibilities have been proposed. Measures of endothelial function, including FMD, are essentially markers of $\mathrm{NO}$ bioavailability ${ }^{(26)}$, and a decrease in $\mathrm{NO}$ production and/or an increase in NO inactivation can result in a decline in FMD. It has been suggested that prior exercise may reduce the postprandial rise in oxidative stress by increasing the body's antioxidant capacity, consequently reducing the inactivation of $\mathrm{NO}$ and so attenuating the decline in $\mathrm{FMD}^{(3)}$. Exercise may also increase endothelial NO synthase mRNA expression and induce phosphorylation of endothelial NO synthase ${ }^{(54)}$, both of which will increase the production of NO, which would attenuate the decline in FMD. Therefore, there are several mechanisms that may explain why exercise reduces the strain experienced by the endothelium following ingestion of high-fat meals.

Due to the study design, it was not possible to determine the mechanisms for the observed exercise-induced reduction in TAG concentration, but, based on other research literature, it appears that exercise reduces TAG concentration through two complementary pathways: an increased clearance of TAG-rich lipoproteins and/or a reduced hepatic secretion of VLDL TAG ${ }^{(15)}$. Recent data from kinetic studies suggest that the predominant cause of exercise-induced reductions in TAG concentration is the increased clearance of TAG-rich lipoproteins, with the increased clearance being mediated by the secretion of fewer but more TAG-rich VLDL particles by the liver following exercise ${ }^{(43,55,56)}$. These TAG-rich VLDL particles are hydrolysed faster by lipoprotein lipase and removed faster from the circulation ${ }^{(57,58)}$. In addition, TAG clearance may be enhanced by increases in skeletal muscle lipoprotein lipase activity after exercise ${ }^{(59,60)}$.

While CVD is typically a chronic problem in which the potentially terminal manifestations, such as myocardial infarction and stroke, usually occur later in the life cycle, the experimental evidence from the present study emphasises that exercise might offer an acceptable, non-pharmacological means of influencing CHD risk when individuals are young. It also implies that interventions that begin early in an individual's life (such as encouraging regular physical activity or exercise) are likely to be beneficial.

A possible limitation of the present study was that smooth muscle function was not assessed. Typically, this is assessed as the dilation of a blood vessel following administration of a single, high dose of nitroglycerin ${ }^{(24)}$. However, given the participant group, the authors elected not to administer nitroglycerin for ethical reasons. Also, it has been argued that repeated administration of nitroglycerin could influence subsequent FMD measurements ${ }^{(61)}$. Furthermore, the dilation following a dose of nitroglycerin has been shown previously to be similar before and after the ingestion of high-fat meals ${ }^{(3,4,31)}$. A further limitation is that only adolescent boys were included in the present study. Future research should be conducted to investigate if similar responses are observed in girls.
In conclusion, $60 \mathrm{~min}$ of moderate-intensity exercise, performed $14 \mathrm{~h}$ before the ingestion of a high-fat breakfast and lunch, attenuated the postprandial endothelial dysfunction that was observed in a control trial where no exercise was performed. These results demonstrate for the first time that meals high in fat place a strain on the endothelium of healthy adolescent boys, but also that exercise has prophylactic properties that negate at least some of the deleterious effects associated with the consumption of these meals.

\section{Acknowledgements}

M. J. S., J. G. M., M. E. N. and L. A. B. designed the research; M. J. S. and L. A. B. conducted the research; M. J. S., J. G. M., M. E. N., K. T., A. N. and L. A. B. analysed the data; M. J. S., J. G. M. and L. A. B. wrote the paper; and L. A. B. had primary responsibility for final content. All authors read and approved the final manuscript. We would like to thank all the boys who participated in the present study along with their parents/ guardians/care givers for their support throughout the study. We would also like to thank the staff at the Woodbrook Vale High School, in particular Mr Ian Smith, for their support. The present study received no specific grant from any funding agency in the public, commercial or not-for-profit sectors. The authors have no conflicts of interest.

\section{References}

1. Gill JM, Al-Mamari A, Ferrell WR, et al. (2004) Effects of prior moderate exercise on postprandial metabolism and vascular function in lean and centrally obese men. J Am Coll Cardiol 44, 2375-2382.

2. Marchesi S, Lupattelli G, Schillaci G, et al. (2000) Impaired flow-mediated vasoactivity during post-prandial phase in young healthy men. Atberosclerosis 153, 397-402.

3. Tyldum GA, Schjerve IE, Tjonna AE, et al. (2009) Endothelial dysfunction induced by post-prandial lipemia: complete protection afforded by high-intensity aerobic interval exercise. J Am Coll Cardiol 53, 200-206.

4. Vogel RA, Corretti MC \& Plotnick GD (1997) Effect of a single high-fat meal on endothelial function in healthy subjects. $A m$ J Cardiol 79, 350-354.

5. Yeboah J, Folsom AR, Burke GL, et al. (2009) Predictive value of brachial flow-mediated dilation for incident cardiovascular events in a population-based study: the multi-ethnic study of atherosclerosis. Circulation 120, 502-509.

6. Bansal S, Buring JE, Rifai N, et al. (2007) Fasting compared with nonfasting triglycerides and risk of cardiovascular events in women. JAMA 298, 309-316.

7. Williams CM (1997) Postprandial lipid metabolism: effects of dietary fatty acids. Proc Nutr Soc 56, 679-692.

8. Strong JP \& Mc Gill HC (1962) The natural history of coronary atherosclerosis. Am J Pathol 40, 37-49.

9. Strong JP (1999) Atherosclerosis in the young: risk and prevention. Hosp Pract 34, 15-16.

10. McGill HC, McMahan CA, Herderick EE, et al. (2000) Origin of atherosclerosis in childhood and adolescence. Am J Clin Nutr 72, 1307S-1315S.

11. Magnussen CG, Niinikoski H, Juonala M, et al. (2012) When and how to start prevention of atherosclerosis? Lessons from the Cardiovascular Risk in the Young Finns Study and the 
Special Turku Coronary Risk Factor Intervention Project. Pediatr Nephrol 27, 1441-1452.

12. Ross R (1999) Atherosclerosis - an inflammatory disease. $N$ Engl J Med 340, 115-126.

13. Juonala M, Viikari JS, Laitinen T, et al. (2004) Interrelations between brachial endothelial function and carotid intimamedia thickness in young adults: the cardiovascular risk in young Finns study. Circulation 110, 2918-2923.

14. Steinberg D (2010) Earlier intervention in the management of hypercholesterolemia: what are we waiting for? J Am Coll Cardiol 56, 627-629.

15. Gill JM \& Hardman AE (2003) Exercise and postprandial lipid metabolism: an update on potential mechanisms and interactions with high-carbohydrate diets (review). J Nutr Biochem 14, 122-132.

16. Rindell MC (2008) The endocrine response and substrate utilization during exercise in children and adolescents. J Appl Physiol 105, 725-733.

17. Barrett LA, Morris JG, Stensel DJ, et al. (2007) Exercise and postprandial plasma triacylglycerol concentrations in healthy adolescent boys. Med Sci Sports Exerc 39, 116-122.

18. MacEneaney OJ, Harrison M, O'Gorman DJ, et al. (2009) Effect of prior exercise on postprandial lipemia and markers of inflammation and endothelial activation in normal weight and overweight adolescent boys. Eur J Appl Physiol 106, $721-729$.

19. Tolfrey K, Bentley C, Goad M, et al. (2012) Effect of energy expenditure on postprandial triacylglycerol in adolescent boys. Eur J Appl Physiol 112, 23-31.

20. Tolfrey K, Doggett A, Boyd C, et al. (2008) Postprandial triacylglycerol in adolescent boys: a case for moderate exercise. Med Sci Sports Exerc 40, 1049-1056.

21. Tanner JM (1989) Foetus into Man: Physical Growth from Conception to Maturity, 2nd ed., pp. 213. Ware: Castlemead Publications

22. Mirwald RL, Baxter-Jones AD, Bailey DA, et al. (2002) An assessment of maturity from anthropometric measurements. Med Sci Sports Exerc 34, 689-694.

23. Frayn KN (1983) Calculation of substrate oxidation rates in vivo from gaseous exchange. J Appl Physiol 55, 628-634.

24. Corretti MC, Anderson TJ, Benjamin EJ, et al. (2002) Guidelines for the ultrasound assessment of endothelial-dependent flow-mediated vasodilation of the brachial artery: a report of the International Brachial Artery Reactivity Task Force. J Am Coll Cardiol 39, 257-265.

25. Harris RA, Nishiyama SK, Wray DW, et al. (2010) Ultrasound assessment of flow-mediated dilation. Hypertension $\mathbf{5 5}$, $1075-1085$.

26. Pyke KE \& Tschakovsky ME (2005) The relationship between shear stress and flow-mediated dilatation: implications for the assessment of endothelial function. J Physiol 568, 357-369.

27. Matthews DR, Hosker JP, Rudenski AS, et al. (1985) Homeostasis model assessment: insulin resistance and beta-cell function from fasting plasma glucose and insulin concentrations in man. Diabetologia 28, 412-419.

28. Winer JB (1971) Statistical Principles in Experimental Design, 2nd ed., pp. 546. New York: McGraw-Hill.

29. Nicholls SJ, Lundman P, Harmer JA, et al. (2006) Consumption of saturated fat impairs the anti-inflammatory properties of high-density lipoproteins and endothelial function. $J \mathrm{Am}$ Coll Cardiol 48, 715-720.

30. Bae JH, Bassenge E, Kim KB, et al. (2001) Postprandial hypertriglyceridemia impairs endothelial function by enhanced oxidant stress. Atherosclerosis 155, 517-523.
31. Gokce N, Duffy SJ, Hunter LM, et al. (2001) Acute hypertriglyceridemia is associated with peripheral vasodilation and increased basal flow in healthy young adults. Am J Cardiol 88, 153-159.

32. Tushuizen ME, Nieuwland R, Scheffer PG, et al. (2006) Two consecutive high-fat meals affect endothelial-dependent vasodilation, oxidative stress and cellular microparticles in healthy men. J Thromb Haemost 4, 1003-1010.

33. Taveras EM, Berkey CS, Rifas-Shiman SL, et al. (2005) Association of consumption of fried food away from home with body mass index and diet quality in older children and adolescents. Pediatrics 116, e518-e524.

34. Schmidt M, Affenito SG, Striegel-Moore R, et al. (2005) Fastfood intake and diet quality in black and white girls: the National Heart, Lung, and Blood Institute Growth and Health Study. Arch Pediatr Adolesc Med 159, 626-631.

35. Raitakari OT, Lai N, Griffiths K, et al. (2000) Enhanced peripheral vasodilation in humans after a fatty meal. $J$ Am Coll Cardiol 36, 417-422.

36. Herrington DM, Fan L, Drum M, et al. (2001) Brachial flowmediated vasodilator responses in population-based research: methods, reproducibility and effects of age, gender and baseline diameter. J Cardiovasc Risk 8, 319-328.

37. Pyke KE, Dwyer EM \& Tschakovsky ME (2004) Impact of controlling shear rate on flow-mediated dilation responses in the brachial artery of humans. J Appl Physiol 97, 499-508.

38. Silber HA, Bluemke DA, Ouyang P, et al. (2001) The relationship between vascular wall shea stress and flow-mediated dilation: endothelial function assessed by phase-contrast magnetic resonance angiography. J Am Coll Cardiol 38, 1859-1865.

39. Thijssen DH, Dawson EA, Black MA, et al. (2008) Heterogeneity in conduit artery function in humans. Am J Physiol Heart Circ Physiol 295, H1927-H1934.

40. Al-Shayji IA, Caslake MJ \& Gill JM (2012) Effects of moderate exercise on $\mathrm{VLDL}_{1}$ and intralipid kinetics in overweight/ obese middle-aged men. Am J Physiol Endocrinol Metab 302, E349-E355.

41. Miyashita M, Burns SF \& Stensel DJ (2006) Exercise and postprandial lipemia: effect of continuous compared with intermittent activity patterns. Am J Clin Nutr 83, 24-29.

42. Anderson RA, Evans LM, Ellis GR, et al. (2006) Prolonged deterioration of endothelial dysfunction in response to postprandial lipaemia is attenuated by vitamin $\mathrm{C}$ in type 2 diabetes. Diabet Med 23, 258-264.

43. Plotnick GD, Corretti MC \& Vogel RA (1997) Effect of antioxidant vitamins on the transient impairment of endotheliumdependent brachial artery vasoactivity following a single high-fat meal. JAMA 278, 1682-1686.

44. Wallace JP, Johnson B, Padilla J, et al. (2010) Postprandial lipaemia, oxidative stress and endothelial function: a review. Int J Clin Pract 64, 389-403.

45. Gill JM, Caslake MJ, McAllister C, et al. (2003) Effects of short-term detraining on postprandial metabolism, endothelial function, and inflammation in endurance trained men: dissociation between changes in triglyceride metabolism and endothelial function. J Clin Endocrinol Metab 88, 4328-4335.

46. Johnson BD, Padilla J, Harris RA, et al. (2011) Vascular consequences of a high-fat meal in physically active and inactive adults. Appl Physiol Nutr Metab 36, 368-375.

47. Amiel SA, Sherwin RS, Simonson DC, et al. (1986) Impaired insulin action in puberty: a contributing factor to poor glycemic control in adolescents with diabetes. $N$ Engl J Med 315 , 215-219. 
48. Moran A, Jacobs DR, Steinberger J, et al. (1999) Insulin resistance during puberty: results from clamp studies in 357 children. Diabetes 48, 2039-2044.

49. Andersen LB, Harro M, Sardinha LB, et al. (2006) Physical activity and clustered cardiovascular risk in children: a cross-sectional study (The European Youth Heart Study). Lancet 368, 399-304.

50. Mitchell MS, Gaul CA, Naylor PJ, et al. (2010) Habitual moderate-to-vigorous physical activity is inversely associated with insulin resistance in Canadian first nations youth. Pediatr Exerc Sci 22, 254-265.

51. Rizzo NS, Ruiz JR, Oja L, et al. (2008) Associations between physical activity, body fat, and insulin resistance (homeostatis model assessment) in adolescents: the European Youth Heart Study. Am J Clin Nutr 87, 586-592.

52. Nassis GP, Papantakou K, Skenderi K, et al. (2005) Aerobic exercise training improves insulin sensitivity without changes in body weight, body fat, adiponectin, and inflammatory markers in overweight and obese girls. Metabolism 54, 1472-1479.

53. van der Heijden GJ, Toffolo G, Manesso E, et al. (2009) Aerobic exercise increases peripheral and hepatic insulin sensitivity in sedentary adolescents. J Clin Endocrinol Metab 94, 4292-4299.

54. Hambrecht R, Adams V, Erbs S, et al. (2003) Regular physical activity improves endothelial function in patients with coronary artery disease by increasing phosphorylation of endothelial nitric oxide synthase. Circulation 107, 3152-3158.

55. Magkos F, Wright DC, Patterson BW, et al. (2006) Lipid metabolism response to a single, prolonged bout of endurance exercise in healthy young men. Am J Physiol Endocrin Metab 290, E355-E362.

56. Tsekouras YE, Yanni AE, Bougatsas D, et al. (2007) A single bout of brisk walking increases basal very low-density lipoprotein triacylglycerol clearance in young men. Metabolism 56, 1037-1043.

57. Fisher RM, Coppack SW, Humphreys SM, et al. (1995) Human triacylglycerol-rich lipoprotein subfractions as substrates for lipoprotein lipase. Clin Chim Acta 236, 7-17.

58. Streja DA (1979) Triglyceride removal from very low density lipoproteins in vivo as a function of their triglyceride content. Atherosclerosis 32, 57-67.

59. Kiens B \& Lithell H (1989) Lipoprotein metabolism influenced by training-induced changes in human skeletal muscle. J Clin Invest 83, 558-564.

60. Malkova D, Evans RD, Frayn KN, et al. (2000) Prior exercise and postprandial substrate extraction across the human leg. Am J Physiol Endocrinol Metab 279, E1020-E1028.

61. Gori T, Harvey P, Floras JS, et al. (2004) Continuous therapy with nitroglycerin impairs endothelium-dependent vasodilation but does not cause tolerance in conductance arteries: a human in vivo study. J Cardiovasc Pharmacol 44, 601-606. 